УДК 316

$10.17213 / 2075-2067-2020-6-120-126$

\title{
ТРАНСФОРМАЦИЯ РИТУАЛОВ \\ В УСЛОВИЯХ РАЗВИТИЯ ИНТЕРНЕТ-ТЕХНОЛОГИЙ
}

\author{
(C) 2020 г. A. A. Синютин \\ Общероссийская общественная организация \\ "Федерация свадебных специалистов России", г. Москва, Россия
}

Целью исследования является обоснование влияния современных информащионных технологий на изменения в ритуальных практиках в ходе осуществления иеремониальноритуальных действий, в частности, на интерпретацию смысла бракосочетания в современной массовой культуре.

Методологическую базу исследования составляют социологическая теория моностилистической и полистилистической культуры Л.Г. Ионина, теория интерактивного ритуала И. Гоффмана, идеи известных мыслителей современности У. Эко, Ю. Хабермаса, необходимые для осмысления рассматриваемой проблематики. Исследование также базируется на исследованиях ритуала российского ученого А. К. Байбурина, а также на ряде современных работ российских ученых, рассматривающих трансформаџию ритуалов в контексте развития интернет-технологий.

Результаты исследования. Переход к полистилизму в производстве культурньх форм, демонополизация сферы творчества культурных норм, расширение технических условий для культурного творчества граждан независимо от уровня их культурной компетенщии, активное включение в эту деятельность широкого слоя пользователей сети Интернет - все эти условия приводят к выхолащиванию сакрального ядра культурных ритуалов. В разрушении ритуалов такого рода активно участвуют большей частью представители молодых поколений - пользователи сети Интернет, но при этом ритуал сохраняется как внешняя форма повседневной деятельности - как иееремониала или как стереотипной формы поведения в конкретных ситуациях.

Перспективу исследования составляет дальнейший соииологический анализ трансформации ритуалов в современном информационном обществе.

Ключевые слова: ритуал; полистилистическая культура; трансформации; интернеттехнологии; свадьба.

\section{TRANSFORMATION OF RITUALS IN THE CONTEXT OF THE DEVELOPMENT OF INTERNET TECHNOLOGIES}

\section{(C) 2020 A. A. Sinyutin}

\section{All-Russian public organization «Federation of wedding specialists of Russia», Moscow, Russia}

The purpose of the research is to substantiate the influence of modern information technologies on changes in ritual practices during the implementation of ceremonial and ritual actions, in particular, on the interpretation of the meaning of marriage in modern mass culture. 
The methodological basis of the research is the sociological theory of monostylistic and polystylistic culture by L. G. Ionin, the theory of interactive ritual by I. Hoffman, and the ideas of famous thinkers of our time U. Eco, Y. Habermas, necessary for understanding the issues under consideration. The research is also based on the research of ritual by the Russian scientist A. K. Baiburin, as well as on a number of modern works of Russian scientists who consider the transformation of rituals in the context of the development of Internet technologies.

Research result. The transition to polystylism in the production of cultural forms, the demonopolization of the sphere of creativity of cultural norms, the expansion of technical conditions for cultural creativity of citizens regardless of their level of cultural competence, the active inclusion of a wide layer of Internet users in this activity - all these conditions lead to the emasculation of the sacred core of cultural rituals. Most of the younger generations - Internet users - are actively involved in the destruction of rituals of this kind. But at the same time, the ritual is preserved as an external form of everyday activity - as a ceremonial or as a stereotypical form of behavior in specific situations.

The perspective of the research is a further sociological analysis of the transformation of rituals in the modern information society.

Key words: ritual; polystylistic culture; transformations; Internet technologies; wedding.

Введение. В ритуалах и обычаях зафиксирована практическая необходимость в тех или иных нормах поведения и деятельности, поскольку они представляют собой стандартизацию действий в различных социальных событиях, укорененных в жизни общества, где посредством ритуалов воспроизводится нормативная культура в повседневной жизни новых поколений. Эти стандарты имеют символико-ценностное содержание, демонстрация которых в действиях индивидов свидетельствует о его/ее приверженности одобряемым культурным нормам. Отказ от тех или иных элементов ритуала как нормативного культурного образца или наполнение ритуальных форм другим содержанием приводят к изменению повседневных форм поведения, поэтому изучение изменений в ритуалах и обычаях, проявляющихся в повседневной жизни людей, «проливает свет на деятельность более крупных социальных систем и институтов» $[1$, с. 96$]$.

Одной из форм проявления изменений в культурно-нормативной системе является смещение ценностно-смыслового компонента в общепринятых ритуалах, что проявляется в коммуникативной сфере и осознается участниками ритуальных действий. Рассмотрение культуры как мира интерсубъективных взаимодействий, которые определяются ори- ентированностью контактирующих субъектов друг на друга, выработку и согласование общих смыслов, определяет также интерпретацию факта изменений в ритуалах: субъекты согласованно меняют смысл своих действий. Наиболее ярко трансформация культуры проявляется в изменении ритуалов, имеющих сакральный смысл (в дюркгеймовской трактовке этого понятия), связанный с коллективной идентичностью.

Трансформации, произошедшие в российском обществе на протяжении последних десятилетий, совпали с периодом бурного развития современных коммуникативных технологий в мире, что повлияло не только на инновационные способы производства, но и на изменение большинства культурных форм, в которые стали вовлекаться различные слои населения.

Ведущие методологические подходы изучения трансформации ритуалов в контексте развития интернет-технологий. Развитие интернет-технологий и формирование компетенций в этой сфере на массовом уровне определили институциональные условия для реализации основных принципов полистилистичной культуры, которые Л. Г. Ионин видел в следующем:

- детотализация; 
- включение;

- ателеологичность [1].

Данные характеристики полистилистической культуры привели к тому, что в условиях бурного развития интернет-технологий расширилось публичное пространство благодаря вовлечению в него огромного количества людей. Согласно известному мыслителю современности Ю. Хабермасу Интернет выступил своеобразным заместителем ранее популярных площадок публичного пространства (городские парки, кафе, дома культуры и т. д.), где происходили различные мероприятия, связанные не только с проведением приятного досуга, но и велись дискуссии по актуальным социальным проблемам. В настоящее время данные функции большей частью переместились в онлайнфорумы и социальные сети, объединяющие индивидов в соответствии с интересами и позволяющие использовать их в любое время суток [2].

Следует отметить, что развитие интернеттехнологий к настоящему времени прошло ряд этапов своего развития. Если на первом этапе развития это был лишь поисковый сервер (Web 1), то уже на втором этапе появляется возможность для креативной деятельности, пользователи смогли создавать свой собственный контент (Web 2). Именно на данном этапе развития начинает формироваться публичное пространство коммуникации. Как отмечают исследователи интернет-коммуникаций, оказалось, что в целом ряде случаев непрофессиональный контент и технология его производства вполне конкурентоспособны в сравнении с деятельностью профессионалов. Например, с появлением фото- и видеокамер в мобильных телефонах человечество превратилось в армию внештатных корреспондентов [3]. Однако появляются и негативные последствия, выразившиеся в основном в переизбытке информационного контента, где стало весьма сложно выделить необходимую и полезную информацию, что было снято в связи с появлением Web 3, получившего название рекомендательного сервиса, поскольку появилась возможность осуществления так называемой «потребительской экспертизы». Данный сервис в состоянии автоматически, в зависимости от предпочтений пользователей, систематизировать информацию в соответствии с разными уровнями вкусов потребителей. По оценкам экспертов, этот тип сервиса формирует колоссальную базу данных, ранжирующих сведения о символической продукции: фильмах, книгах, театральных постановках, личных событиях. «И все эти данные имеют персональную привязку, они не разрознены, не деперсонализированы, как это было раньше, а объединены во вкусовые профили десятков тысяч людей. Такого рода сведения... никогда не были доступны в таком объеме... Система выдает рекомендации по самым разным областям культуры и досуга; впервые задействован механизм кросс-культурных рекомендаций» [3, с. 92]. При этом создатели контента получили возможность зарабатывать самостоятельно деньги, независимо от продавцов и потребителей контента (рекламная модель, абонентская плата и др.), что активизирует и стимулирует творческую активность миллионов пользователей. В этих условиях для многих пользователей социальных сетей стираются барьеры, ограничивающие публикацию тех или иных материалов, важно, что они поднимут рейтинг страницы автора. Естественно, что такие возможности делают социальные сети необыкновенно востребованными. Так, например, в 2018 году средние показатели активности российских пользователей в сети ВКонтакте составило 24 миллиона, а в Instagram до 25 миллионов [4].

Помимо того, что современные интернеттехнологии непосредственно влияют на креативную коммуникативную деятельность огромного количества индивидов и формирование вкусов (особенно у молодого поколения), они выступают мощным регулятором социального поведения в реальной (а не виртуальной) жизни, что приводит к увеличению субъектов нормотворчества. При этом пользователи социальных сетей выступают творцами норм социального поведения в сети, которые закрепляются посредством массового одобрения (лайков) круга пользователей примерно одного профиля.

Исследователи, занимающиеся анализом контента и возможностями сетевых коммуникаций, подчеркивают, что постоянные коммуникации в них создают ряд психологических проблем, возникающих в процессе увеличения коммуникативных возможностей активных пользователей. Так, В.А. Бейнен- 
сон среди наиболее значимых проблем выделяет следующие:

- осознание собственной силы оказывать влияние на мнения и настроения своей группы и широкой общественности;

- возникновение и закрепление «эффекта растормаживания», обладающего как позитивными, так и негативными сторонами, последние ведут к снижению значимости культурных норм и признанных в реальном обществе авторитетов культурного производства. Он пишет: «Любой пользователь в Сети имеет равные условия, чтобы заработать виртуальный статус, приобрести влияние, часто не связанное с уровнем заслуг в реальности. В сети, где есть ощущение равноправных отношений и авторитаризм сведен к минимуму, люди гораздо более склонны высказываться откровенно и нарушать нормы приличия» [5, с. 411].

Одним из видимых социальных последствий укоренения коммуникативных онлайнтехнологий как элемента нашей повседневности стало стирание границ между публичным и приватным пространством, чему способствовала специализация платформы Instagram на обмене визуальным контентом, а это привело к тому, что всего за один год с 2017 по 2018 количество участников возросло в два раза [4]. Как показывают данные современных исследований, проведенных в отношении анализа восприятия приватного пространства нынешним молодым поколением, нормой жизни которого стали практики самопрезентации в Instagram, происходит стремительное сокращение приватного пространства. Если ранее считалось аморальным выставлять напоказ события своей личной жизни, то теперь это превращается в норму социального поведения, «...а причиной отсутствия стыда при публикациях - то, что общество одобряет подобные демонстрации, становится все более свободным от негласных запретов на такие “заявления”. ... Фотографии обнажившихся пользователей занимают первое место среди прочих публикаций личного пространства, а фотографии интимных сцен - третье. Это доказывает популярность фотографий такой тематики, которая демонстрирует нам все более "раскрепощающееся" общество» [6, с. 37]. Известный мыслитель современности У. Эко в этой связи подчеркивает социокультурный эффект разрушения границы между публичным и приватным: «Исчезает конфиденциальность - значит, мир привыкает к ее исчезновению. Защита конфиденциальности - проблема не только юридическая, но и моральная, и антропологически-культурная. Нам следует учиться вырабатывать, распространять, воспитывать новое представление о сдержанности по отношению к себе и к другим» [7, с. 166].

Стремление открыть свою частную жизнь приводит к предельной открытости публикаций социально одобряемых событий личной жизни, событий-праздников. Пожалуй, что самым популярным таким событием-праздником является свадьба, сопровождаемая определенными ритуалами в любой культуре, поскольку является значимым переходом индивида из одного статуса в другой. Известный российский исследователь свадебных ритуалов в традиционных восточнославянских культурах А.К. Байбурин подчеркивал, что «вступление в брак - это не только оформление семейных отношений, переход в новый статус, но и предписанный культурой способ разрешения противоречия между способностью к продолжению рода и необходимостью получения на это социальной санкции» $[8$, с. 66]. При этом вступление заключающих брак в новую фазу жизни и осознание связанных с ней трудностей обусловливали оформление свадебной церемонии множеством символических ритуалов и знаковых примет, несущих, прежде всего, сакральный смысл - совершение таинства, который определял закрытость (приватность) значительной части свадебной церемонии, несмотря на то, что в целом она имела публичный характер. Не случайно в большом количестве традиционных культур главные действующие лица - жених и невеста либо присутствуют очень ограниченное время в начале брачной церемонии, либо не присутствуют на ней вообще.

Влияние интернет-технологий на трансформацию свадебных ритуалов. В современных условиях размывания границы приватной и публичной сфер жизни доминирование установки на самопрезентацию через визуализацию деталей повседневной жизни, позиционирование потребительских практик своей жизни, в число которых обязательно 
входят праздники и развлечения, публикация свадебных ритуалов стала распространенной практикой интернет-пользователей. Собственное или профессиональное режиссирование свадебного события приводит к выхолащиванию из него именно сакрального ядра, ранее охраняемого социальным субъектом, будь то церковь, община, соответствующий социальный круг или государство.

В индивидуальном измерении свадебный ритуал связан с изменением социального статуса личности, что требует также изменения идентичности. Благодаря этому содержанию свадьбу относят к ритуалам перехода. При наличии доктринальной основы, т. е. смысла культурной формы (в данном случае - морального учения о предназначении семьи, четкого описания ролевых требований к мужу и жене, их обязанностям по отношению к детям, родителям, роду и др.), которая признается, поддерживается и контролируется обществом, поведенческие формы соответствуют культурным предписаниям.

Современное смещение акцента в интерпретации брака на его индивидуально-личностный характер привело к реинтерпретации свадьбы. Теперь это событие рассматривается как явление сугубо индивидуальной жизни, обусловленное психологическими потребностями индивида. Л. Ионин так определил это явление: «Эти формы можно назвать свободно парящими: они не связаны в их нынешнем состоянии с социальными интересами и через них с определенными слоями и группами. Теперь, когда отсутствует запрет на публичную презентацию, они предлагают себя каждому, кто обеспокоен поиском идентичности, стремится обрести новый целостный образ мира, в котором можно четко фиксировать собственное место» [1, с. 277].

Свадебный ритуал становится удачной формой презентации индивида, поскольку в этих условиях допускаются различные сценарные решения: от соблюдения традиционной культурной формы до эпатажных театрализованных решений, не ориентированных на воспроизводство или рождение каких-либо новых культурных форм (как, например, это было при введени «комсомольской свадьбы»). Широкие возможности современных цифровых технологий, видеотехники и сетевых платформ позволяют использовать риту- ал в варианте карнавального действия, спектакля. Отметим, что и в этом случае достигается эффект утверждения новой идентичности или дополнительных ее характеристик. Однако это действие приобретает диаметрально противоположный смысл: включаясь в свадебный ритуал в качестве главного субъекта (жениха или невесты), индивид мотивируется собственными потребностями, часто не связанными с представлениями об институте семьи. Достаточно распространенной практикой в настоящее время является организация свадебной церемонии не как публичного события, фиксирующего принятие новой социальной роли и связанных с ней функций и ответственности, а как некой сцены, используемой для самовыражения и оказания впечатления на других.

По сути, свадебный ритуал используется в качестве возможности публично сыграть главную роль в спектакле и произвести позитивное впечатление на других. И это впечатление может быть связано не с будущей семейной жизнью (на что собственно направлен свадебный ритуал), а с самопрезентацией каких-либо собственных — реальных или желаемых — характеристик: привлекательности, статусности, успешности, креативности, финансовой обеспеченности, социального лидерства, которое подтверждается готовностью к слому культурных стереотипов (вседозволенности) и пр. Смысл подобного рода знаково-коммуникативной деятельности индивида И. Гоффман связывал с осознанным или неосознанным «стремлением контролировать поведение других, особенно их ответной реакции на его действия» [8, с. 35]. В этом контексте не лишним будет напомнить, что в современном информационном обществе эффективность управления впечатлением может быть монетизирована, что и показывают медийные практики селебрити (celebrit), поэтому многие свадьбы, представленные на платформах Web 2.0 и Web 3.0, презентуются как спектакль, даже в том случае, если реальной свадебной церемонии не было и брачующиеся ограничились лишь фотосессией.

Заключение. Проведенный анализ показывает, что в настоящее время при сохранении ритуально-церемониальных действий, 
связанных с проведением свадебного торжества, его символико-коммуникационная сфера претерпела значительные изменения, которые свидетельствуют о происходящих культурных изменениях. Новые ритуально-символические элементы широко обсуждаются в обществе, и в частности, в блогосфере. Иными словами, в настоящее время сохраняется символико-ритуальное оформление (т.е. культурная форма) события, но трансформируется его социально-смысловое наполнение (доктрина). При этом сам ритуал выступает реализацией культурной формы и свидетельствует об устойчивости положенной в ее основу доктрины.

Анализ позиционирования новых элементов сакральных ритуалов, а также коллективных представлений об этом имеет значение для теоретического осмысления вектора культурных изменений в изменившихся социокультурных условиях России, которые проявляются не только в трансформации социальной структуры, включении широких социальных слоев в культурные коммуникации, но и в информатизации социокультурного пространства. Последний фактор обусловливает включение широких слоев в производство новых элементов ритуалов, их селекцию и широкое тиражирование этих образцов посредством инструментов блогосферы и все расширяющихся возможностей социальных сетей.

\section{Литература}

1. Гидденс Э. Социология. Изд. 2-е. М.: Едиториал УРС, 2005.

2. Ионин Л.Г. Социология культуры. М.: Изд. Дом ГУ ВШЭ, 2004.

3. Breslow H. Civil Society, Political Economy and the Internet // Virtual Culture: Identity and Communication in Cybersociety. - London: Sage, 1997. - P. 236-257.

4. Lievrouw L., Livingstone $S$. The Handbook of New Media: Social Shaping and Social Consequences of ICTs. - London: Sage, 2006.

5. Статистика авторов социальных сетей [Электронный ресурс] // Brand Analytics. Режим доступа: https://br-analytics.ru/statistics/ author/.

6. Бейненсон В.A. Актуальные проблемы медиапсихологии в условиях системы
Web 2.0 // Вестник Нижегородского университета им. Н.И. Лобачевского. Сер. Социология. Психология. Философия. — 2014 . №1 (2). - С. 407-415.

7. Мельников М. В., Моисеева 3. Ф. Граница между личным и публичным пространством и ее особенности на примере социальной сети Instagram // Теория и практика общественного развития. — 2016. - №10. C. 31-39.

8. Эк. У. Утраченная укромность частной жизни // Эко У. Полный назад! «Горячие войны» и популизм в СМИ. - М.: Эксмо, 2007.

9. Байбурин A.K. Ритуал в традиционной культуре. Структурно-семантический анализ восточнославянских обрядов. - СПб: Наука, 1993.

10. Гоффман И. Представление себя другим в повседневной жизни. - М.: КанонПресс, 2000.

\section{References}

1. Giddens Je. Sociologija [Sociology]. Izd. 2-e. - Moscow: Editorial URS, 2005.

2. Ionin L. G. Sociologija kul'tury [Sociology of culture]. - Moscow: Izd. Dom GU VShJe, 2004.

3. Breslow H. Civil Society, Political Economy and the Internet // Virtual Culture: Identity and Communication in Cybersociety. - London: Sage, 1997. — P. 236-257.

4. Lievrouw L., Livingstone S. The Handbook of New Media: Social Shaping and Social Consequences of ICTs. - London: Sage, 2006.

5. Statistika avtorov social'nyh setej [Statistics of authors of social networks] [Jelektronnyj resurs] // Brand Analytics. — URL: https://branalytics.ru/statistics/author/.

6. Bejnenson V.A. Aktual'nye problemy mediapsihologii $\mathrm{v}$ uslovijah sistemy Web 2.0 [Actual problems of media psychology in the conditions of the Web 2.0 system] // Vestnik Nizhegorodskogo universiteta im. N.I. Lobachevskogo. Ser. Sociologija. Psihologija. Filosofija [Sociology. Psychology. Philosophy]. — 2014. №1 (2). - Pp. 407-415.

7. Mel'nikov M. V., Moiseeva Z.F. Granica mezhdu lichnym i publichnym prostranstvom i ee osobennosti na primere social'noj seti Instagram [The border between personal and public space and its features on the example of the so- 
cial network Instagram] // Teorija i praktika obshhestvennogo razvitija [Theory and practice of social development]. — 2016. — №10. Pp.31-39.

8. Jeko U. Utrachennaja ukromnost' chastnoj zhizni [Lost privacy] // Jeko U. Polnyj nazad! «Gorjachie vojny» i populizm v SMI [Full back! «Hot wars» and populism in the media]. - Moscow: Jeksmo, 2007.
9. Bajburin A.K. Ritual v tradicionnoj kul'ture. Strukturno-semanticheskij analiz vostochnoslavjanskih obrjadov [Ritual in traditional culture. Structural and semantic analysis of East Slavic rites]. — Saint-Petersburg: Nauka, 1993.

10. Goffman I. Predstavlenie sebja drugim v povsednevnoj zhizni [Presenting yourself to others in everyday life]. - Moscow: Kanon-Press, 2000.

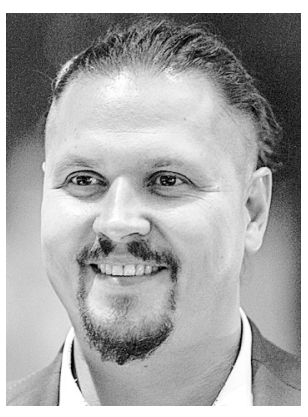

Синютин Александр Александрович - президент Общероссийской общественной организации «Федерация свадебных специалистов России». Выпускник МГИМО (У) МИД РФ. Автор 15 обучающих программ по психологии и бизнесу в сфере культурно-массовых мероприятий.

Sinyutin Alexander Alexandrovich - President of the AllRussian public organization «Federation of wedding specialists of Russia». Graduate of MGIMO (U) MFA of the Russian Federation. Author of 15 training programs on psychology and business in the field of cultural events.

115470, г. Москва, пр. Андропова, 17, корп. 1, кв. 159

17 Andropova av., bld. 1, ap. 159, 115470, Moscow, Russia

E- mail: ssinyutin@mail.ru 